\title{
Adsorption of phenylacetylene on $\mathrm{Si}(100)-2 \times 1$ : Reaction mechanism and formation of a styrene-like $\pi$-conjugation system
}

\author{
Feng Tao, ${ }^{1}$ Ming Hua Qiao, ${ }^{2}$ Zhen Hua Li, ${ }^{2}$ Lei Yang, ${ }^{1}$ Yu Jing Dai, ${ }^{1}$ Hai Gou Huang, ${ }^{1}$ and Guo Qin Xu ${ }^{1}$,* \\ ${ }^{1}$ Department of Chemistry, National University of Singapore, 10 Kent Ridge, Singapore, 119260 \\ ${ }^{2}$ Department of Chemistry, Fudan University, Shanghai, People's Republic of China, 200433
}

(Received 26 September 2002; published 27 March 2003)

\begin{abstract}
The interactions of phentylacetylene and phenylacetylene- $\alpha-d_{1}$ with $\operatorname{Si}(100)-2 \times 1$ have been studied as a model system to mechanistically understand the adsorption of conjugated $\pi$-electron aromatic substitutions on $\operatorname{Si}(100)-2 \times 1$. Vibrational signatures show that phenylacetylene covalently binds to the surface through a [ 2 $+2]$-like cycloaddition pathway between the external $\mathrm{C} \equiv \mathrm{C}$ and $\mathrm{Si}=\mathrm{Si}$ dimer, forming styrene-like conjugation structure which was further supported by the chemical-shift of $\mathrm{C} 1 s$ core level. These experimental results are consistent with the density-functional theory [B3LYP/6-311//+ G(d)] calculations. The resulting styrenelike conjugation structures may possibly be employed as an intermediate for further organic syntheses and fabrication of molecular architecture for modification and functionalization of Si surfaces, or as a monomer for polymerization on $\mathrm{Si}$ surfaces.
\end{abstract}

DOI: 10.1103/PhysRevB.67.115334

PACS number(s): 68.43.Fg, 82.65.+r

\section{INTRODUCTION}

Organic functionalization of semiconductor surfaces ${ }^{1-9}$ has great potential applications in the development of sensitive Si-based nanosensors ${ }^{10}$ and synthesis of ultrathin organic films for advanced optical, electronic, and biorelated devices. $^{7-10}$

To successfully incorporate molecular functionalities into device fabrication, the most important step is to gain a thorough understanding for the formation mechanisms and binding structure of multifunctional organic molecules on Si surfaces and create precursor templates with desired reactive functionalities for further developing multilayered Si-based molecular systems. Most of the previous work in this area focused on the studies of attachment chemistry of some simple unsaturated hydrocarbons on Si surfaces. ${ }^{2}$ However, in order to extend the organic modification and functionalization to allow for the next-layer growth, multifunctional molecules are preferred for initial binding. Upon covalent binding, this layer acting as a precursor, in turn, should retain or newly produce (during the interaction with $\mathrm{Si}$ surfaces) one or more reactive functional groups for the further binding of other organic molecules. The formation of surface intermediates containing delocalized $\pi$-electron structures is of particular interest due to the possibility of synthesizing larger oligomers and polymers known as semiconductors or metals ${ }^{11,12}$ through their conjugated structures in vacuum.

$\mathrm{Si}(100)-2 \times 1$ is a semiconductor surface of technological importance. In its $(2 \times 1)$ reconstructed structure, ${ }^{13}$ adjacent $\mathrm{Si}$ atoms pair into $\mathrm{Si}=\mathrm{Si}$ dimers, shown in Fig. 1(a). The bonding within a surface dimer can be formally described in the terms of a $\sigma$ bond coupled with a $\pi$ bond, analogous to the $\mathrm{C}=\mathrm{C}$ double bonds of alkenes, suggesting a possible similarity of chemical reactivities between them. Due to the large Si-Si distance and bending back bonds that connect the surface dimer with the bulk atoms, the $\pi$ bond in a $\mathrm{Si}=\mathrm{Si}$ dimer is quite weak. In fact, the $\mathrm{Si}=\mathrm{Si}$ dimer might be regarded as a di radical as schematically presented in Fig. 1(b).
Previous studies showed that simple organic molecules containing $\mathrm{C}=\mathrm{C}$ can be covalently bound to $\mathrm{Si}(100)-2 \times 1$ by a so-called "asymmetric [2+2] cycloaddition." ${ }^{14-20}$ The asymmetric geometry of ground-state dimers allows the [2 +2 ] reaction to proceed through an asymmetric pathway, where alkene approaches the titled $\mathrm{Si}=\mathrm{Si}$ dimer from one side [Fig. 1(c)]. This asymmetric approach is of lower symmetry and can occur with a lower energy barrier. Conjugated dienes or multienes ${ }^{21-24}$ can be covalently bonded to Si(100)- $2 \times 1$ through $[4+2]$-like or/and $[2+2]$-like cycloaddition strategies. For six-membered aromatic molecules and their substitutions, ${ }^{25-34}$ their binding mechanisms are

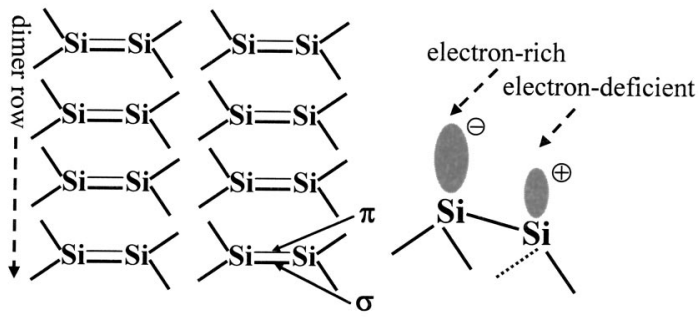

(a)

(b)

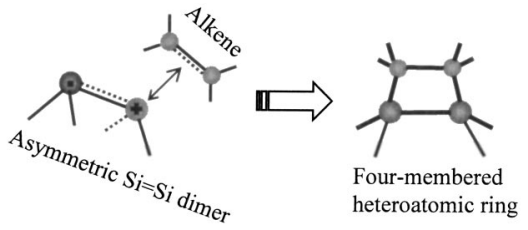

(c)

FIG. 1. (a) The surface structure of $\mathrm{Si}(100)-2 \times 1$, (b) the scheme of buckling $\mathrm{Si}=\mathrm{Si}$ dimer and (c) the schematic presentation of asymmetric [2+2] cycloaddition for alkene to $\operatorname{Si}(100)-2 \times 1$. 
more complicated. It was suggested that benzene can bind to $\mathrm{Si}(100)$ through both [4+2]-like or/and tight-bridge tetrasigma binding modes. ${ }^{25}$ For pyridine on $\mathrm{Si}(100),{ }^{35}$ dativebonded pyridine via $\mathrm{Si}: \mathrm{N}$ and [4+2]-like cycloadduct involving both $\mathrm{N}^{1}$ and $\mathrm{C}^{4}$ are coexistent at low temperatures. At $350 \mathrm{~K}$, dative-bonded molecules possibly convert to $d i$ sigma binding configuration.

As a typical substitution of aromatic hydrocarbons, phenylacetylene is made of phenyl ring and conjugated $\mathrm{C} \equiv \mathrm{C}$ group. Investigating its interaction with $\mathrm{Si}$ surfaces will provide the correlation of reaction selectivity and binding configuration with the individual functional groups in a multifunctional molecule, offering the necessary flexibility in functionalization and modification of silicon surfaces.

In this experiment, high-resolution electron-energy-loss spectroscopy (HREELS) and x-ray photoelectron spectroscopy (XPS) were employed to characterize the vibrational and electronic properties of phenylacetylene and phenylacetylene- $\alpha-d_{1}$ on Si(100)- $2 \times 1$, respectively. Density Functional Theory (DFT) calculations were commanded to optimize the chemisorption geometries and calculate their adsorption energies. Our results show that phenylacetylene is covalently bound to $\mathrm{Si}(100)-2 \times 1$ through a [2+2]-like cycloaddition of the $\mathrm{C} \equiv \mathrm{C}$ with a $\mathrm{Si}=\mathrm{Si}$ dimer, forming a styrene-like conjugation structure. The resulting conjugation structures may be considered as a precursor for further syntheses, modification, and creation of multilayer molecular architectures on silicon surfaces.

\section{EXPERIMENT}

The experiments were performed in two separate UHV chambers. Both of them have a base pressure of $<2$ $\times 10^{-10}$ Torr, achieved with turbomolecular and sputteredion pumps. The investigation of vibrational properties was carried out in a HREELS chamber with a high-resolution electron-energy-loss spectrometer (HREELS, LK-2000-14R) and a quadruple mass spectrometer (UTI-100) for gas analysis. HREELS spectra were taken in a specular geometry on both the clean and phenylacetylene adsorbed samples with primary beam energy of $5.0 \mathrm{eV}$. A resolution of $\sim 50 \mathrm{~cm}^{-1}$ [full width at half maximum (FWHM) for the elastic peak] can be routinely achieved. The off-specular spectra were also collected at off-specular directions of $\Delta \theta$, where the $\Delta \theta$ refers to the angle of $\theta_{\text {(analyzer) }}-\theta_{\text {(specular) }}$.

The second UHV chamber was mainly equipped with an $\mathrm{x}$-ray gun (both $\mathrm{Mg}$ and $\mathrm{Al}$ anodes) and hemispherical electron energy analyzer (CLAM 2, VG) for XPS. In the studies of $\mathrm{C} 1 s$ photoemission, the $\mathrm{Mg}$-anode $\mathrm{x}$-ray source ( $h \nu$ $=1253.6 \mathrm{eV}$ ) was used. The binging energy (BE) scale of all the spectra presented in this paper is referenced to the peak maximum of the Si $2 p$ line ( $99.3 \mathrm{eV}$ calibrated for $\mathrm{Au} 4 f_{7 / 2}$ ) (Ref. 36) of $\mathrm{Si}(100)-2 \times 1$ with a FWHM lower than $1.3 \mathrm{eV}$. The $\mathrm{C} 1 \mathrm{~s}$ photoemission spectra of physisorbed multilayer and saturated chemisorption monolayer were fitted with VGX900 (VG Scientific, UK). During the fitting, the full width at half maximum (FWHM) of each peak was kept at $1.25 \mathrm{eV}$ which is the typical resolution of $\mathrm{C} 1 s$ core-level for our XPS system

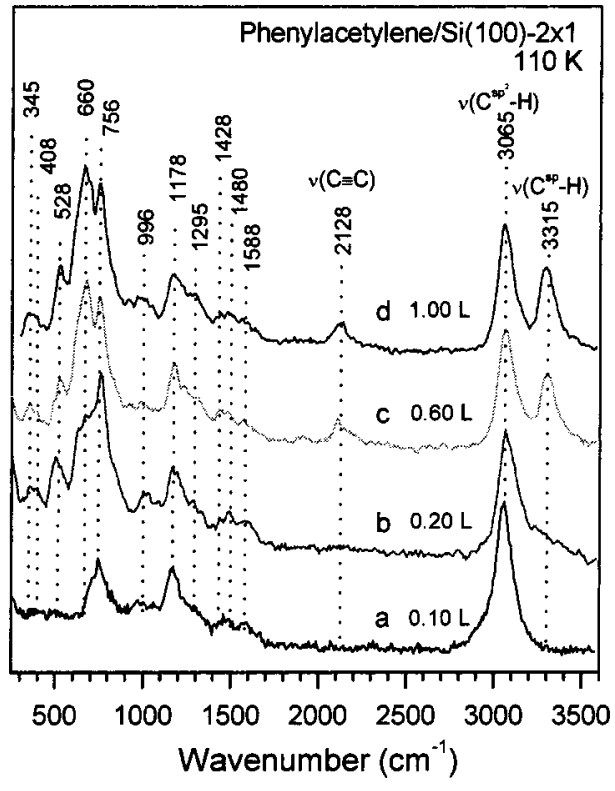

FIG. 2. HREELS spectra of phenylaceetylene-exposed $\mathrm{Si}(100)-2 \times 1$ at $110 \mathrm{~K}$ as a function of exposure.

The samples with a dimension of $8 \times 18 \times 0.38 \mathrm{~mm}^{3}$ were cut from $n$-type $\mathrm{Si}(100)$ wafers (Phosphors doped, with a resistivity of 1-30 $\Omega \mathrm{cm}, 99.999 \%$, Goodfellow). A Ta-sheet heater ( $0.025 \mathrm{~mm}$ thick, Goodfellow) was sandwiched tightly between two $\mathrm{Si}(100)$ crystals held together by two Ta clips. A 0.003-in W-5\% Re/W-26\% Re thermocouple was attached to the center of the one of the silicon samples using a hightemperature ceramic adhesive (Aremco 516) for temperature measurement and control. Uniform heating of the samples was achieved by passing current through the Ta heater. This sample-mounting configuration allows us to resistively heat the sample to $1400 \mathrm{~K}$ and conductively cool them to $110 \mathrm{~K}$ using liquid nitrogen. The temperature distribution on the samples is within $\pm 10 \mathrm{~K}$ at $1000 \mathrm{~K}$, determined using a pyrometer ( $\varepsilon=0.74$, TR-630, Minolta).

The sample was carefully cleaned by cycles of $\mathrm{Ar}^{+}$sputtering and annealing to $1300 \mathrm{~K}$ for $15-20 \mathrm{~min}$. Phenylacetylene $\left(99 \%\right.$, Aldrich) and Phenylacetylene- $\alpha-d_{1}(99$ at. \% D, Aldrich) were further purified by several freeze-pump-thaw cycles before being dosed onto the silicon surface through a Varian adjustable leak valve. Exposures were calculated and reported in Langmuir ( $1 \mathrm{~L}=10^{-6}$ Torr s) without ion gauge sensitivity calibration.

\section{RESULTS AND DISCUSSION}

\section{A. High-resolution electron-energy-loss spectroscopy}

Figure 2 shows the high-resolution electron-energy-loss spectra of phenylacetylene-exposed $\mathrm{Si}(100)-2 \times 1$ at $110 \mathrm{~K}$ as a function of exposure. The vibrational frequencies and their assignments for physisorbed and chemisorbed molecules are summarized in Table I. Vibrational signatures at $345,408,528,660,756,996,1178,1295,1428,1480,1588$, 2128,3065 , and $3315 \mathrm{~cm}^{-1}$ can be clearly identified in the spectrum of physisorbed molecules. Table I shows that the 
TABLE I. The assignments of HREELS spectra of physisorbed and saturated chemisorption phenylacetylene on $\mathrm{Si}(100)-2 \times 1$. All frequencies are in $\mathrm{cm}^{-1}$. Phys.: physisorbed molecules; Chem.: Chemisorbed molecules.

\begin{tabular}{|c|c|c|c|c|c|c|c|}
\hline Designation & Description & Liquid $^{\mathrm{a}}$ & Phys. & Chem. & Isotope $^{a}$ & Phys. & Chem \\
\hline \multirow[t]{2}{*}{$\nu_{1}$} & $\nu \equiv \mathrm{C}-\mathrm{H}(\mathrm{D})$ & 3332 & 3315 & & 2609 & 2578 & \\
\hline & $\nu=\mathrm{C}-\mathrm{D}$ & & & & & & 2218 \\
\hline$\nu_{25}$ & $\nu \mathrm{C}-\mathrm{H}$ & 3096 & & & 3096 & & \\
\hline$\nu_{2}$ & $\nu \mathrm{C}-\mathrm{H}$ & 3078 & & & 3078 & & \\
\hline$\nu_{3}$ & $\nu \mathrm{C}-\mathrm{H}$ & 3067 & 3065 & 3060 & 3066 & 3067 & 3052 \\
\hline$\nu_{26}$ & $\nu \mathrm{C}-\mathrm{H}$ & 3058 & & & 3058 & & \\
\hline$\nu_{4}$ & $\nu \mathrm{C}-\mathrm{H}$ & 3047 & & & 3046 & & \\
\hline \multirow[t]{2}{*}{$\nu_{5}$} & $\nu \mathrm{C} \equiv \mathrm{C}$ & 2120 & 2128 & & 1984 & 1984 & \\
\hline & $\nu \mathrm{C}=\mathrm{C}$ & & & 1630 & & & 1618 \\
\hline$\nu_{6}$ & $\nu \mathrm{C}-\mathrm{C}$ & 1601 & 1588 & 1589 & 1600 & 1582 & 1588 \\
\hline$\nu_{27}$ & $\nu \mathrm{C}-\mathrm{C}$ & 1573 & & & 1573 & & \\
\hline$\nu_{7}$ & $\nu \mathrm{C}-\mathrm{C}$ & 1488 & 1480 & 1484 & 1488 & 1485 & 1480 \\
\hline$\nu_{28}$ & $\nu \mathrm{C}-\mathrm{C}$ & 1447 & 1428 & 1426 & 1447 & 1429 & 1425 \\
\hline$\nu_{29}$ & $\nu \mathrm{C}-\mathrm{C}$ & 1330 & & & 1329 & & \\
\hline$\nu_{30}$ & $\beta \mathrm{C}-\mathrm{H}$ & 1282 & 1295 & 1298 & 1278 & 1288 & 1288 \\
\hline$\nu_{8}$ & $\nu \mathrm{C}-\mathrm{CCH}$ & 1192 & & & 1193 & 1206 & \\
\hline$\nu_{9}$ & $\beta \mathrm{C}-\mathrm{H}$ & 1175 & 1178 & 1168 & 1175 & 1165 & 1160 \\
\hline$\nu_{31}$ & $\beta \mathrm{C}-\mathrm{H}$ & 1157 & & & 1157 & & \\
\hline$\nu_{32}$ & $\beta \mathrm{C}-\mathrm{H}$ & 1070 & & 1065 & 1070 & & \\
\hline$\nu_{10}$ & $\beta \mathrm{C}-\mathrm{H}$ & 1028 & & & 1025 & & \\
\hline$\nu_{11}$ & ring breath & 998 & 996 & 988 & 998 & & \\
\hline$\nu_{17}$ & $\gamma \mathrm{C}-\mathrm{H}$ & 985 & & & 985 & 1002 & \\
\hline$\nu_{14}$ & $\gamma \mathrm{C}-\mathrm{H}$ & 968 & & & 968 & & 963 \\
\hline$\nu_{18}$ & $\gamma \mathrm{C}-\mathrm{H}$ & 915 & & & 916 & & \\
\hline$\nu_{15}$ & $\gamma \mathrm{C}-\mathrm{H}$ & 842 & & & 841 & & \\
\hline$\nu_{12}$ & $\alpha \mathrm{C}-\mathrm{C}-\mathrm{C}$ & 760 & 756 & 745 & 758 & 758 & 752 \\
\hline$\nu_{19}$ & $\gamma \mathrm{C}-\mathrm{H}$ & 756 & & & 758 & & \\
\hline$\nu_{20}$ & $\phi \mathrm{C}-\mathrm{C}$ & 689 & 660 & & 691 & 695 & 687 \\
\hline$\nu_{33}$ & $\beta C C-H(D)$ & 649 & & & 482 & & \\
\hline$\nu_{34}$ & $\alpha \mathrm{C}-\mathrm{C}-\mathrm{C}$ & 613 & & & 623 & & \\
\hline$\nu_{21}$ & $\gamma \mathrm{CC}-\mathrm{H}(\mathrm{D})$ & 613 & & & 482 & & \\
\hline$\nu_{22}$ & $\phi \mathrm{C}-\mathrm{C}$ & 530 & 528 & & 531 & 523 & \\
\hline \multirow[t]{2}{*}{$\nu_{35}$} & $\beta(\mathrm{C}-\mathrm{C} \equiv \mathrm{C})$ & 513 & & & 531 & & \\
\hline & $\nu \mathrm{Si}-\mathrm{C}$ & & & 510 & & & 515 \\
\hline$\nu_{13}$ & $\alpha \mathrm{C}-\mathrm{C}-\mathrm{C}$ & 465 & & & 459 & & \\
\hline$\nu_{16}$ & $\phi \mathrm{C}-\mathrm{C}$ & 418 & 408 & 396 & 419 & & \\
\hline$\nu_{23}$ & $\gamma \mathrm{C}-\mathrm{CCH}$ & 349 & 345 & & 340 & 350 & \\
\hline$\nu_{36}$ & $\beta \mathrm{C}-\mathrm{CCH}$ & 349 & & & 340 & & \\
\hline$\nu_{24}$ & $\gamma \mathrm{C}-\mathrm{C} \equiv \mathrm{C}$ & 162 & & & 154 & & \\
\hline
\end{tabular}

${ }^{\mathrm{a}}$ Reference 37.

vibrational features of physisorbed phenylacetylene [Figs. 2(c) and (d)] are in excellent agreement with the IR spectrum of liquid phenyacetylene. ${ }^{37}$ Among these vibrational signatures of physisorbed molecules, the peak at $3315 \mathrm{~cm}^{-1}$ is assigned to the $\mathrm{C}^{s p}-\mathrm{H}(-\mathrm{C} \equiv \mathrm{CH})$ stretching mode; the loss feature at $3065 \mathrm{~cm}^{-1}$ is attributable to the stretching mode of $\mathrm{C}^{p^{2}}-\mathrm{H}$ on phenyl ring; the $\mathrm{C} \equiv \mathrm{C}$ stretching mode can account for the feature at $2128 \mathrm{~cm}^{-1}$; vibrational features around 1588, 1480, 1428, and $1295 \mathrm{~cm}^{-1}$ are associated with the characteristic vibrational modes of monosubstituted phenyl ring. ${ }^{38,39}$
The vibrational features of chemisorbed phenylacetylene at low exposures [Fig. 2(a)] are obtained by annealing the multilayer phenylacetylene-exposed sample to $300 \mathrm{~K}$ to drive away all the physisorbed molecules and only retain the chemisorbed molecules [Fig. 3(b)], however, are significantly different. Losses at 396, 510, 745, 988, 1065, 1168, $1298,1426,1484,1589,1630$, and $3060 \mathrm{~cm}^{-1}$ can be readily resolved. The absence of observable $\mathrm{Si}-\mathrm{H}$ stretching around 2000-2100 $\mathrm{cm}^{-1}$ (Ref. 40) suggests the nature of molecular chemisorption for phenylacetylene on $\mathrm{Si}(100)-2 \times 1$. Compared to physisorbed molecules, the vibrational peak around 


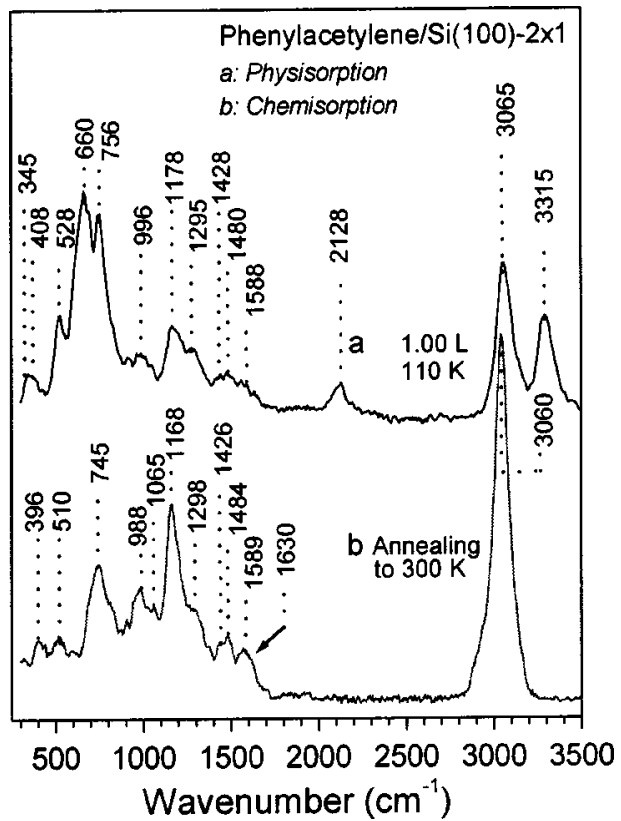

FIG. 3. HREELS spectra of the physisorbed multilayer (a) and saturated chemisorption monolayer (b) of phenylacetylene on $\operatorname{Si}(100)-2 \times 1$.

$3315 \mathrm{~cm}^{-1}$ associated to $\mathrm{C}^{s p}-\mathrm{H}$ (in $-\mathrm{C} \equiv \mathrm{CH}$ ) stretching mode is absent in chemisorbed molecules, demonstrating the rehybridization of carbon atoms of the $\mathrm{C} \equiv \mathrm{C}$ group and their involvement in binding with the $\mathrm{Si}$ surface. This is further supported by the absence of $\mathrm{C} \equiv \mathrm{C}$ stretching mode around $2128 \mathrm{~cm}^{-1}$ in the vibrational signatures of chemisorbed phenylacetylene [Figs. 2(a) and 3(b)]. In addition, a new peak at $1630 \mathrm{~cm}^{-1}$ attributed to $\mathrm{C}=\mathrm{C}$ double bond can be identified although its relative intensity is low possibly due to its nearly parallel orientation. ${ }^{41}$ Another change is the appearance of a new peak at $\sim 510 \mathrm{~cm}^{-1}$, ascribed to $\mathrm{Si}-\mathrm{C}$ stretching mode. ${ }^{42}$ Furthermore, the characteristic vibrational modes $[\nu(\mathrm{C}-\mathrm{C})]$ of monosubstituted phenyl ring around 1580-1650 $\mathrm{cm}^{-1}$, $1450-1525 \mathrm{~cm}^{-1}$, and $1280-1350 \mathrm{~cm}^{-1}$ are preserved in the HREELS spectra of chemisorbed phenylacetylene [Fig. 3(b)], indicating the retention of aromaticity of phenyl ring. The fact of no observable intensities around $2900 \mathrm{~cm}^{-1} \mathrm{sug}$ gests that there are no carbon atoms rehybridizing from $s p^{2}$ or $s p$ into $s p^{3}$ after chemisorption, further supporting the preservation of phenyl ring upon chemisorption.

The absence of $\mathrm{C}^{s p}-\mathrm{H}$ and $\mathrm{C} \equiv \mathrm{C}$ stretching modes in chemisorbed molecules indicates the direct involvement of $\mathrm{C} \equiv \mathrm{C}$ group in the reaction with $\mathrm{Si}=\mathrm{Si}$ dimer. The negligible vibrational feature for $\mathrm{C}^{s p 3}-\mathrm{H}$ stretching mode at $<3000 \mathrm{~cm}^{-1}$ together with retention of the characteristic vibrational modes $[\nu(\mathrm{C}-\mathrm{C})]$ of monosubstituted phenyl ring demonstrates that the chemical binding occurs mainly through the external $\mathrm{C} \equiv \mathrm{C}$ group. Thus the $[2+2]$-like cycloaddition between $\mathrm{C} \equiv \mathrm{C}$ group and $\mathrm{Si}$ dimer is the proposed binding mode.

For further understanding the reaction mechanism and clarifying binding structure for phenylacetylene on $\operatorname{Si}(100)-2 \times 1$, phenylacetylene- $\alpha-d_{1}$ was also employed in our HREELS experiments. Figures 4(a) and (b) present the

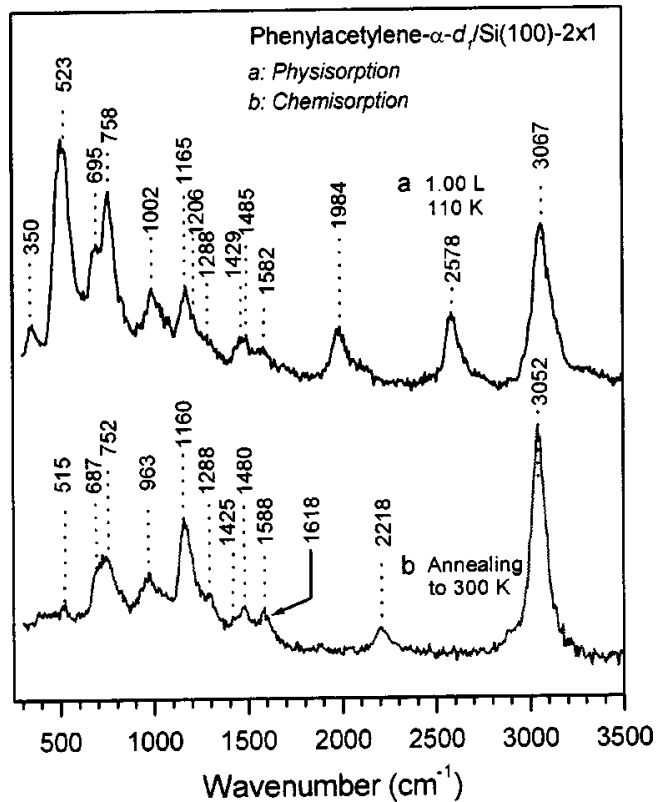

FIG. 4. HREELS spectra of the physisorbed multilayer (a) and saturated chemisorption monolayer (b) of phenylacetylen- $\alpha-d_{1}$ on $\operatorname{Si}(100)-2 \times 1$.

vibrational features of physisorbed and saturated chemisorption phenylacetylene- $\alpha-d_{1}$ on $\operatorname{Si}(100)-2 \times 1$, respectively. In Fig. 4(a), vibrational peaks at 350, 523, 695, 758, 1002, 1165, 1206, 1288, 1429, 1485, 1582, 1984, 2578, and 3067 are clearly resolved. Their assignments listed in Table I show that the vibrational features of physisorbed molecules are in good accordance with the IR spectrum of liquid phenylacetylene- $\alpha-d_{1} \cdot{ }^{37}$ Among these vibrational signatures, the two peaks at 2578 and $1984 \mathrm{~cm}^{-1}$ are assigned to $\mathrm{C}^{\alpha(s p)}-\mathrm{D}(-\mathrm{C} \equiv \mathrm{CD})$ and $\mathrm{C} \equiv \mathrm{C}$ stretching modes, respectively. The feature at $3067 \mathrm{~cm}^{-1}$ is ascribed to the $\mathrm{C}^{s p 2}-\mathrm{H}$ stretching of phenyl ring. For chemisorbed molecules, both $\mathrm{C}^{\alpha(s p)}-\mathrm{D}$ and $\mathrm{C}^{\alpha} \equiv \mathrm{C}^{\beta}$ stretching modes at $\sim 2578$ and $\sim 1984 \mathrm{~cm}^{-1}$, respectively, are absent. However, a new peak appears around $2218 \mathrm{~cm}^{-1}$, attributable to the $\mathrm{C}^{s p 2}-\mathrm{D}$ stretching mode. ${ }^{43}$ Indeed, these changes occurred at C-D and $\mathrm{C}-\mathrm{H}$ stretching regions upon chemisorption of phenylacetylene- $\alpha-d_{1}$ strongly support the conclusion that only $\mathrm{C} \equiv \mathrm{C}$ bond directly participates in the covalent binding with the silicon surface.

Figure 5 presents seven possible binding modes of phenylacetylene on $\mathrm{Si}(100)-2 \times 1$. Among them, modes I, II, III, $\mathrm{IV}$, and $\mathrm{V}$ are the cycloadducts between phenyl ring and $\mathrm{Si}$ surface dangling bonds by $[2+2]$-like or $[4+2]$-like reaction schemes. Their $\mathrm{C}-\mathrm{H}$ stretching features would present two separate peaks corresponding to $\mathrm{C}^{s p^{3}}-\mathrm{H}$ and $\mathrm{C}^{s p^{2}}-\mathrm{H}$ together with $\mathrm{C}^{s p}-\mathrm{D}$ stretching remaining at the similar frequency (at $\sim 2578 \mathrm{~cm}^{-1}$ ) to that of physisorbed phenylacetylene- $\alpha-d_{1}$. However, our experimental results (Fig. 4) exclude the occurrence of these possibilities. In mode VI, both external $-\mathrm{C} \equiv \mathrm{CH}$ and its conjugated internal $\mathrm{C}=\mathrm{C}$ of phenyl ring take part in the covalent attachment with the $\mathrm{Si}=\mathrm{Si}$ dimer through $[4+2]$-like addition strategy. In the resulting configuration, the $\mathrm{C}^{\alpha}$ rehybridizes from $s p$ to 


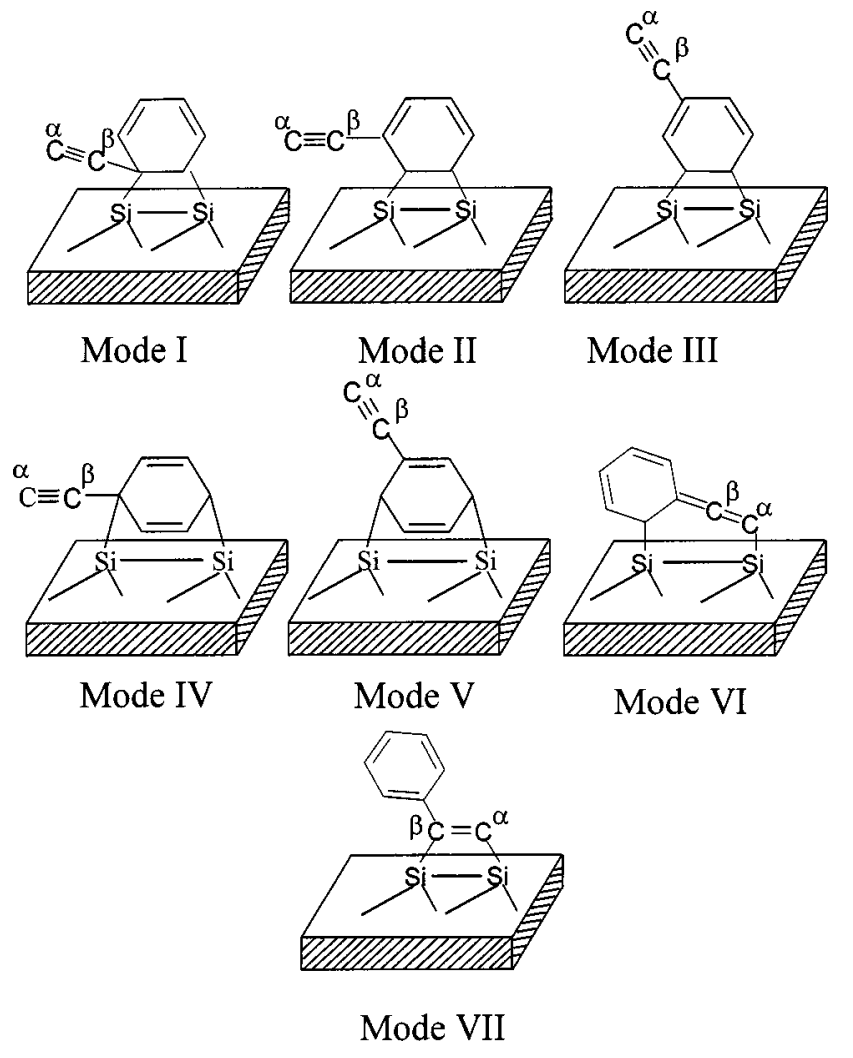

FIG. 5. The schematic diagram of seven possible binding modes of phenylacetylene covalently bound to $\operatorname{Si}(100)-2 \times 1$.

$s p^{2}$ and one carbon atom of phenyl ring changes from $s p^{2}$ to $s p^{3}$. Thus the disappearance of both $\mathrm{C}^{s p}-\mathrm{H}$ stretching feature and the characteristic vibrational peaks of monosubstituted phenyl ring would be expected in chemisorbed molecules. The $\mathrm{C}^{s p 3}-\mathrm{H}$ stretching at $<3000 \mathrm{~cm}^{-1}$ would be concurrently observed with the $\mathrm{C}^{s p 2}-\mathrm{H}$ stretching around 3050 $\mathrm{cm}^{-1}$. In fact, our major experimental evidences of (i) the disappearance of both $\mathrm{C}^{s p}-\mathrm{H}$ and $\mathrm{C} \equiv \mathrm{C}$ stretching modes, (ii) only $\mathrm{C}-\mathrm{H}$ stretching mode around $3050 \mathrm{~cm}^{-1}\left(\mathrm{C}^{s p 2}-\mathrm{H}\right.$ stretching), and (iii) the preservation of characteristic vibrational modes of monosubstituted phenyl ring, eliminate the possibility of mode VI. In addition, due to the absence of $\mathrm{C}^{s p 3}-\mathrm{H}(\mathrm{D})$ stretching mode in Figs. 3(b) and 4(b), a tetra- $\sigma$ binding mode, similar to acetylene on $\mathrm{Si}(100)-2 \times 1$, can be ruled out. ${ }^{44-47}$ Our experimental spectra can be well interpreted with the proposed mode VII, the $[2+2]$-like cycloaddition pathway involving the $\mathrm{C} \equiv \mathrm{C}$ group and one $\mathrm{Si}=\mathrm{Si}$ dimer. In this binding mode, due to the rehybridization of $\mathrm{C}^{\alpha}$ and $\mathrm{C}^{\beta}$ atoms from $s p$ to $s p^{2}$, all the carbon atoms in the chemisorbed molecules have a $s p^{2}$ configuration, resulting in a single C-H stretching peak around $3060 \mathrm{~cm}^{-1}$ in the spectra of chemisorbed phenylacetylene. The $\mathrm{C}^{\alpha}$-D stretching in phenylacetylene- $\alpha-d_{1}$ will significantly down-shifts from $2578 \mathrm{~cm}^{-1}$ ascribed to $\mathrm{C}^{s p}-\mathrm{D}$ for physisorbed molecules to $2218 \mathrm{~cm}^{-1}$ attributed to the $\mathrm{C}^{s p^{2}}-\mathrm{D}$ stretching mode ${ }^{43}$ due to the direct involvement of $\mathrm{C} \equiv \mathrm{C}$ in the surface reaction. This binding configuration is further supported by the absence of $\mathrm{C} \equiv \mathrm{C}$ stretching modes at $1984 \mathrm{~cm}^{-1}$ [Fig. 4(b)]. Moreover, the retention of characteristic vibrational features of mono-

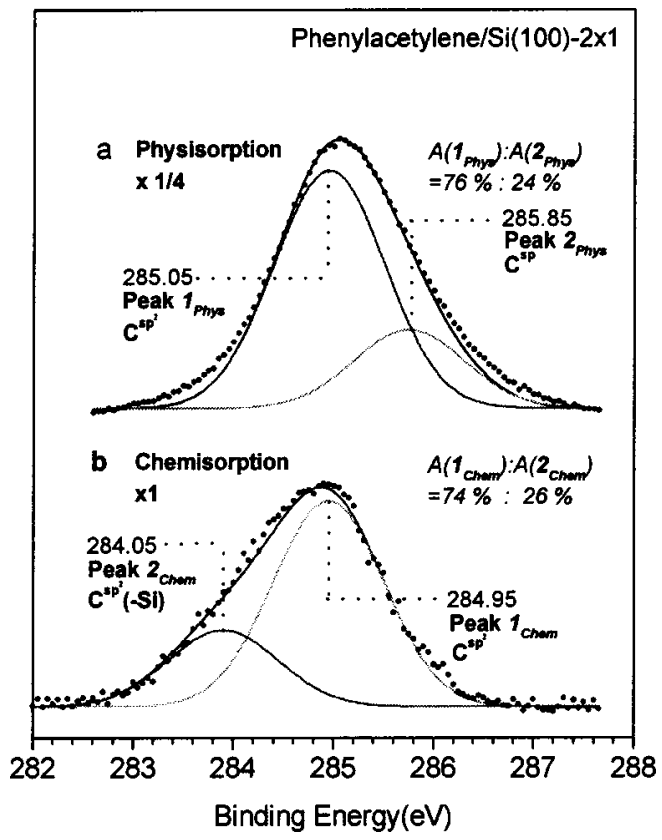

FIG. 6. C $1 s$ experimental spectra and their deconvoluted results of physisorbed multilayer (a) and saturated chemisorption monolayer (b) on $\mathrm{Si}(100)-2 \times 1$.

substituted phenyl ring upon chemisorption shows that phenyl ring does not directly interact with the Si surface. Based on these experimental evidences, it is reasonable to propose that phenylacetylene covalently binds to $\mathrm{Si}(100)-2 \times 1$ through $[2+2]$-like cycloaddition between the $\mathrm{C} \equiv \mathrm{C}$ group and $\mathrm{Si}=\mathrm{Si}$ dimer.

\section{B. X-ray photoelectron spectroscopy}

XPS was employed to investigate the chemical shifts of $\mathrm{C}$ $1 s$ core level of phenylacetylene on $\mathrm{Si}(100)-2 \times 1$. C $1 s$ photoemission feature for physisorbed multilayer on $\mathrm{Si}(100)-2 \times 1$ is presented in Fig. 6(a). Figure 6(b) is the C $1 s$ spectra for saturated chemisorption monolayer on $\mathrm{Si}(100)-2 \times 1$ obtained by annealing the multilayer phenylacetylene covered sample to $300 \mathrm{~K}$ to drive away physisorbed phenylacetylene and only remain chemisorbed molecules. For both systems, the experimental C $1 \mathrm{~s}$ spectra display an asymmetric peak shape, possibly due to the existence of inequivalent carbon atoms. In order to assign $\mathrm{C} 1 s$ peaks of physisorbed and chemisorbed phenylacetylene, software VGX900 (VG) (Ref. 48) was commanded to deconvolute the XPS spectra. The fitting results presented in Fig. 6 show that the $\mathrm{C} 1 \mathrm{~s}$ peak for physisorbed phenylacetylene can be reasonably deconvoluted into two peaks at 285.85 and $285.05 \mathrm{eV}$ with an area ratio of $\sim 1: 3$, assigned to the $\mathrm{C}$ $\equiv \mathrm{C}$ group and phenyl ring, respectively. Similarly, C $1 s$ photoemission feature of chemisorbed molecules can be fitted into two peaks at 284.95 and $284.05 \mathrm{eV}$ with an intensity ratio of $\sim 3: 1$. According to the HREELS results, chemisorbed phenylscetylene has a styrene-like skeleton. In this structure, six $\mathrm{C}$ atoms of phenyl ring maintain their $s p^{2}$ hybridization upon chemisorption; the other two $\mathrm{C}$ atoms with the hybridization of $s p^{2}$ are covalently linked to surface sili- 
TABLE II. Adsorption energies of the local minima in the phenylacetylene/ $\mathrm{Si}_{9} \mathrm{H}_{12}$ model system from B3LYP/6-311+ G(d). All energies are in $\mathrm{kcal} \mathrm{mol}^{-1}$.

\begin{tabular}{cccccccc}
\hline \hline Reactive functionality & Phenyl ring & Phenyl ring & Phenyl ring & Phenyl ring & Phenyl ring & $-\mathrm{C}=\mathrm{C}-\mathrm{C} \equiv \mathrm{C}-$ & $\mathrm{C} \equiv \mathrm{C}$ \\
\hline Binging mode in Fig. 5 & I & II & III & IV & V & VI & VII \\
Reaction mechanism & {$[2+2]-$ like } & {$[2+2]-$ like } & {$[2+2]-$ like } & {$[4+2]-$ like } & {$[4+2]-$ like } & {$[4+2]-$ like } & {$[2+2]-$ like } \\
Adsorption energy & -0.4 & 5.3 & 3.8 & 15.8 & 20.9 & 27.0 & 54.9 \\
\hline \hline
\end{tabular}

Adsorption energy is calculated by subtracting the energy of cluster $\left(\mathrm{C}_{8} \mathrm{H}_{6} / \mathrm{Si}_{9} \mathrm{H}_{12}\right)$ from the total energy of free substrate cluster $\left(\mathrm{Si}_{9} \mathrm{H}_{12}\right)$ and gas phase phenylacetylene $\left(\mathrm{C}_{8} \mathrm{H}_{6}\right)$.

con atoms. Thus the peaks at 284.95 and 284.05 can be reasonably assigned to the $\mathrm{C}$ atoms of phenyl ring and those of external group $\left[-(\mathrm{Si}) \mathrm{C}^{\alpha}=\mathrm{C}^{\beta}(\mathrm{Si}) \mathrm{H}\right]$, respectively. Compared to physisorbed molecules, the $\mathrm{C} 1 s$ core level of phenyl ring does not display obvious chemical shift, which also suggests that phenyl ring is not directly involved in the binding with $\mathrm{Si}$ surfaces. However, the binding energy of $\mathrm{C}^{\alpha}$ and $\mathrm{C}^{\beta}$ significantly shifts down by $1.8 \mathrm{eV}$ due to their rehybridization from $s p$ to $s p^{2}$ and covalent binding to $\mathrm{Si}$ atoms with a lower electronegativity. Thus our XPS results are consistent with vibrational analyses and further confirm the direct participation of $\mathrm{C} \equiv \mathrm{C}$ in the cycloaddition with $\mathrm{Si}=\mathrm{Si}$ dimers.

\section{DFT calculations}

In general, there are seven possible binding modes for phenylacetylene chemically binding on $\mathrm{Si}(100)$, schematically presented in Fig. 5. The direct interaction between phenyl ring and Si dimer is presented in modes $\mathrm{I}-\mathrm{V}$. In addition, there are other two possibilities including the $[4+2]$-like cyclic addition involving both the external $\mathrm{C} \equiv \mathrm{C}$ group and its conjugated $\mathrm{C}=\mathrm{C}$ on phenyl ring (mode $\mathrm{VI}$ ) and the direct participation of the external $\mathrm{C} \equiv \mathrm{C}$ group via a $[2+2]$-like cycloaddition pathway (mode VII). Our DFT studies focus on the geometric optimization and adsorption energy calculation for further understanding our experimental results.

We performed DFT calculations using GAUSSIAN 94 (Ref. 49) for a phenylacetylene molecule adsorbed onto a starting cluster of $\mathrm{Si}_{9} \mathrm{H}_{12}$. This cluster with one exposed $\mathrm{Si}=\mathrm{Si}$ dimer was successfully used in several previous studies. ${ }^{50-53}$ Based on the possible binding modes shown in Fig. 5, seven phenylacetylene-bonded calculation clusters (not shown) were built to model their corresponding cycloadducts. All
DFT studies are single point energy calculation of B3LYP/6-311+G(d) on the fully optimized geometry of B3LYP/6-31G(d). The calculated adsorption energies of binding modes I-VII are listed in Table II. It is unambiguous that the product of $[2+2]$-like cycloaddition reaction occurring between the external $\mathrm{C} \equiv \mathrm{C}$ group and $\mathrm{Si}=\mathrm{Si}$ dimer (mode VII) has the largest adsorption energy. Its value is also much higher than that of $[4+2]$-like cycloadduct (mode VI) involving both $\mathrm{C} \equiv \mathrm{C}$ and its conjugated $\mathrm{C}=\mathrm{C}$ bond on phenyl ring. The calculation result clearly shows that the energetically preferred reaction mechanism for phenylacetylene is distinctly different from the [4+2]-like cycloaddition for typical conjugated dienes on $\mathrm{Si}(100)-2 \times 1$, such as 1,3-cyclohexadiene ${ }^{21-23}$ and 1,3-butadiene. ${ }^{24}$ However, this preferable $[2+2]$ cycloaddition mechanism for phenylacetylene is similar to benzonitrile on $\mathrm{Si}(100)-2 \times 1$ via the [2 $+2]$-like approach occurring at $\mathrm{C} \equiv \mathrm{N}$ group to form a benzoimine-like conjugation skeleton. ${ }^{34}$ In both cases, the cycloaddition results in an energetically stable aromatic skeleton on surfaces.

\section{SUMMARY}

Our experimental results together with DFT calculations have shown the formation of styrene-like conjugation structures for phenylacetylene on $\mathrm{Si}(100)-2 \times 1$ through the $[2$ +2 ]-like addition reaction scheme between the external $\mathrm{C}$ $\equiv \mathrm{C}$ group and $\mathrm{Si}=\mathrm{Si}$ dimer. The formed styrene-like skeleton may possibly be employed as a precursor for further chemical modification and functionalization of silicon surfaces, an intermediate for organic syntheses in vacuum, or as a monomer for fabrication of conductive polymer thin films on semiconductors. ${ }^{11-12,54}$
*Corresponding author. Fax: (65) 6779 1691; email address: chmxugq@nus.edu.sg

${ }^{1}$ J. T. Yates, Jr., Science 279, 335 (1998).

${ }^{2}$ R. A. Wolkow, Annu. Rev. Phys. Chem. 50, 413 (1999).

${ }^{3}$ J. M. Buriak, Chem. Commun. (Cambridge) 12, 1051 (1999).

${ }^{4}$ H. N. Waltenburg and J. T. Yates, Jr., Chem. Rev. 95, 1589 (1995).

${ }^{5}$ J. G. Ekerdt, Y. M. Sun, A. Szabo, G. J. Szulczewski, and J. M. White, Chem. Rev. 96, 1499 (1996).

${ }^{6}$ L. C. Chen, K. H. Chen, J. J. Wu, D. M. Bhusari, and M. C. Lin, Silicon-Based Materials and Devices: Materials and Processing, edited by H. S. Nalwa (Academic, New York, 2001), Vol. 1.

${ }^{7}$ Y. Cui and C. M. Lieber, Science 291, 851 (2001).
${ }^{8}$ T. H. Lee, Sci. Am. (Int. Ed.) 286, 52 (2002).

${ }^{9}$ H. G. Craighead, Science 290, 1532 (2000).

${ }^{10}$ Y. Cui, Q. Wei, H. Park, and C. M. Lieber, Science 293, 1289 (2001).

${ }^{11}$ T. A. Skotheim, Handbook of Conducting Polymers (Marcel Dekker, New York, 1986).

${ }^{12}$ H. S. Nalwa, Handbook of Organic Conductive Molecules and Polymers (John Wiley \& Sons, New York, 1997).

${ }^{13}$ K. Takayanagi, Y. Tanishiro, and M. Takahashi, Surf. Sci. 164, 367 (1985); K. Takayanagi, T. Tanishiro, S. Tanahashi, and M. J. Takahashi, J. Vac. Sci. Technol. A 3, 1502 (1985).

${ }^{14}$ H. B. Liu and R. J. Hamers, J. Am. Chem. Soc. 119, 7593 (1997).

${ }^{15}$ S. F. Bent, Surf. Sci. 500, 879 (2002). 
${ }^{16}$ R. J. Hamers, S. K. Coulter, M. D. Ellison, J. S. Hovis, D. F. Padowitz, M. P. Schwartz, C. M. Greenlief, and J. N. Russell, Acc. Chem. Res. 33, 617 (2000).

${ }^{17}$ M. H. Qiao, F. Tao, Y. Cao, Q. Liu, Z. H. Li, W. L. Dai, J. F. Deng, and G. Q. Xu, J. Chem. Phys. 114, 2766 (2001).

${ }^{18}$ M. H. Qiao, Y. Cao, F. Tao, J. F. Deng, and G. Q. Xu, J. Phys. Chem. B 104, 11211 (2000).

${ }^{19}$ M. H. Qiao, Y. Cao, J. F. Deng, and G. Q. Xu, Chem. Phys. Lett. 325, 508 (2000).

${ }^{20}$ F. Tao, W. S. Sim, G. Q. Xu, and M. H. Qiao, J. Am. Chem. Soc. 123, 9397 (2001).

${ }^{21}$ R. Konency and D. J. Doren, Surf. Sci. 417, 169 (1998).

${ }^{22}$ J. S. Hovis, H. B. Liu, and R. J. Hamers, J. Phys. Chem. B 102, 6873 (1998).

${ }^{23}$ J. S. Hovis, H. B. Liu, and R. J. Hamers, Surf. Sci. 404, 1 (1998).

${ }^{24}$ A. V. Teplyakov, M. J. Kong, and S. F. Bent, J. Chem. Phys. 108, 4599 (1998).

${ }^{25}$ Y. Tahuchi, M. Fujisawa, T. Takaoka, T. Okada, and M. Nishijima, J. Chem. Phys. 95, 6870 (1991).

${ }^{26}$ B. I. Craig, Surf. Sci. 280, L279 (1993).

${ }^{27}$ G. P. Lopinski, D. J. Moffatt, and R. A. Wolkow, Chem. Phys. Lett. 282, 305 (1998).

${ }^{28}$ B. Borovsky, M. Krueger, and E. Ganz, Phys. Rev. B 57, R4269 (1998).

${ }^{29}$ S. Gokhole, P. Trischberger, D. Menzel, W. Widdra, H. Droge, H. P. Steinruck, U. Brikenheuer, U. Gutdeutsch, and N. Rosch, J. Chem. Phys. 108, 5554 (1998).

${ }^{30}$ P. L. Silverstrelli, F. Ancilotto, and F. Toiogo, Phys. Rev. B 62, 1596 (2000).

${ }^{31}$ M. Staufer, U. Birkenheuer, T. Belling, F. Nortemann, N. Rosch, W. Widdra, K. I. Kostov, T. Moritz, and D. Menzel, J. Chem. Phys. 112, 2498 (2000).

${ }^{32}$ M. D. Ellison and R. J. Hamers, J. Phys. Chem. B 103, 6243 (1999)

${ }^{33}$ S. K. Coulter, J. S. Hovis, M. D. Ellison, and R. J. Hamers, J. Vac. Sci. Technol. A 18, 1965 (2000).

${ }^{34}$ F. Tao, Z. H. Wang, and G. Q. Xu, J. Phys. Chem. B 106, 3557 (2002).

${ }^{35}$ F. Tao, M. H. Qiao, Z. H. Wang, and G. Q. Xu (unpublished).

${ }^{36}$ J. F. Moulder, W. F. Stickle, and K. D. Bomben, Handbook of $X$-ray Photoelectron Spectroscopy (Perkin-Elmer Corporation, Minnesota, 1992).

${ }^{37}$ G. W. King and S. P. So, J. Mol. Spectrosc. 36, 468 (1970).

${ }^{38}$ L. V. Daimay, B. C. Norman, G. F. William, and G. G. Jeanette,
The Handbook of Infrared and Raman Characteristic Frequencies of Organic Molecules (Academic, Boston, 1991).

${ }^{39}$ G. Varsanyi and S. Szoke, Vibrational Spectra of Benzene Derivates (Academic, New York \& London, 1969).

${ }^{40}$ H. Wagner, R. Butz, and U. Backes, D. Bruchmann, Solid State Commun. 38, 1155 (1981).

${ }^{41}$ H. Ibach, D. L. Mills, Electron Energy Loss Spectroscopy and Surface Vibrations (Academic, New York, 1982).

${ }^{42}$ K. Hamaguchi, S. Machida, M. Nagao, F. Yasui, K. Mukai, Y. Yamashita, and J. Yoshinobu, J. Phys. Chem. B 105, 3718 (2001).

${ }^{43}$ D. A. Condirston and J. D. Laposa, J. Mol. Spectrosc. 42, 466 (1976).

${ }^{44}$ R. Miotto, A. C. Ferraz, and G. P. Srivastava, Phys. Rev. B 65, 075401 (2002).

${ }^{45}$ W. Kim, H. Kim, G. Lee, Y. K. Hong, K. Lee, C. Hwang, D. H. Kim, and J. Y. Koo, Phys. Rev. B 64, 193313 (2001).

${ }^{46}$ X. Lu and M. C. Lin, Phys. Chem. Chem. Phys. 2, 4213 (2000).

${ }^{47}$ S. H. Xu, Y. Yang, M. Keeffe, G. J. Lapeyre, and E. Rotenberg, Phys. Rev. B 60, 11586 (1999).

${ }^{48}$ VG Microtech Ltd., VGX900-Real and Protected Mode Programs, UK, 1994.

${ }^{49}$ M. J. Frisch, G. W. Trucks, H. B. Schlegel, P. M. W. Gill, B. G. Johnson, M. A. Robb, J. R. Cheeseman, T. Keith, G. A. Petersson, J. A. Montgomery, K. Raghavachari, M. A. Al-Laham, V. G. Zakrzewski, J. V. Ortiz, J. B. Foresman, J. Cioslowski, B. B. Stefanov, A. Nanayakkara, M. Challacombe, C. Y. Peng, P. Y. Ayala, W. Chen, M. W. Wong, J. L. Andres, E. S. Replogle, R. Gomperts, R. L. Martin, D. J. Fox, J. S. Binkley, D. J. Defrees, J. Baker, J. P. Stewart, M. Head-Gordon, C. Gonzalez, and J. A. Pople, Gaussian 94, Rev. C. W (Gaussian, Inc. Pittsburgh, PA, 1995).

${ }^{50}$ T. Kato, S. Y. Kang, X. Xu, and T. Yamabe, J. Phys. Chem. B 105, 10340 (2001).

${ }^{51}$ X. Xu, S. Y. Kang, and T. Yamabe, Bull. Chem. Soc. Jpn. 74, 817 (2001).

${ }^{52}$ P. L. Silvestrelli, F. Ancilotto, and F. Toigo, Phys. Rev. B 62, 1596 (2000).

${ }^{53}$ H. A. Hofer, A. J. Fisher, G. P. Lopinski, and R. A. Wolkow, Phys. Rev. B 63, 085314 (2001).

${ }^{54}$ I. Capek, J. Hernandez-Barajas, D. Hunkelev, J. L. Reddinger, J. R. Reynolds, and C. Wandrey, Radical Polymerisation Polyelectrolytes (Springer, New York \& Berlin, 1999). 